\title{
Impacts of COVID-19 on Liver Cancers: During and after the Pandemic
}

\author{
Stephen Lam Chan ${ }^{\mathrm{a}}$ b Masatoshi Kudo $^{c}$ \\ a State Key Laboratory of Translational Oncology, Department of Clinical Oncology, Sir \\ YK Pao Centre for Cancer, Institute of Digestive Disease, The Chinese University of Hong \\ Kong, Hong Kong, Hong Kong; ${ }^{b}$ Hand in Hand Cancer Foundation, Hong Kong, Hong Kong; \\ 'Department of Gastroenterology and Hepatology, Faculty of Medicine, Kindai University, \\ Osakasayama, Japan
}

\author{
Keywords \\ Hepatocellular carcinoma · Pandemic · Virology · Cirrhosis
}

\begin{abstract}
Background: The pandemic of coronavirus disease 2019 (COVID-19) has diverted resources from healthcare services for patients with chronic medical illness such as cancer. COVID-19 also causes organ dysfunction, complicating cancer treatment. In most countries with an outbreak of COVID-19, modifications of cancer management have been adopted to accommodate the crisis and minimize the exposure of cancer patients to the infection. In countries where COVID-19 numbers are subsiding, medical teams should also be prepared to resume normal practices gradually. Here, we aim to review the literature on the impact of COVID-19 on patients with hepatocellular carcinoma (HCC) as well as discuss modifications to the management of HCC during and after recovery from the pandemic. Summary: Based on current data, $10-40 \%$ of patients with COVID-19 have hepatic injury characterized by an elevation of transaminases and/or hyperbilirubinemia. Multiple mechanisms contribute to the hepatic injury, including direct viral entry to hepatocytes/cholangiocytes, immune-mediated hepatitis, hypoxia, and drug-related hepatotoxicity. In patients with HCC, COVID-19 may exacerbate existing chronic liver disease and complicate the management of cancer. Cancer patients generally have a higher risk of infection and worse outcome, especially those who have recently undergone cancer treatment. Although HCC is under-represented in COVID-19 series, mitigation measures should be implemented to minimize the exposure of patients to the virus. $A$ decision on the treatment of HCC should be balanced with consideration of the availability of medical resources, the level of infection risk of COVID-19, and the risk-benefit ratio of the individual patient. In areas where the COVID-19 outbreak is subsiding, clinicians should be pre-
\end{abstract}


pared to manage a surge of HCC patients with higher disease burdens and complications. Key Messages: Mitigation measures to protect at-risk patients, such as those with cancers, from SARS-CoV-2 infection should be exercised and the impact of COVID-19 on this group of patients should be thoroughly studied.

(c) 2020 The Author(s)

Published by S. Karger AG, Basel

\section{Introduction}

Coronavirus disease 2019 (COVID-19), caused by the severe acute respiratory syndrome coronavirus 2 (SARS-CoV-2), has led to a global pandemic in 2020. As of July 26, 2020, more than 15 million people have been diagnosed COVID-19 with over 600,000 deaths [1]. The pandemic has placed huge pressure on the healthcare system globally. Apart from influences on specialties of general medicine and critical care, clinical services of cancer patients have also been significantly affected in multiple aspects. Firstly, the time-critical nature of diagnosis for COVID-19 and the large number of patients requiring hospital admission have inevitably diverted resources away from existing cancer services. In particular, up to $20 \%$ of patients with COVID-19 infection require intensive care and/or assisted ventilation support, resulting in a shortage of anesthetists for surgeries related to cancers [2-4]. This problem is worse in areas with major outbreaks, where medical staff from multiple specialties are temporarily recruited to manage COVID-19 or triage patients with fever. Secondly, cancer patients frequently require close follow-up for antineoplastic treatment and monitoring of toxicity. Therefore, they are prone to both community and nosocomial exposure to SARS-CoV-2 during travel to medical facilities. Furthermore, epidemiological data suggest that cancer patients are more susceptible to infection with SARS-CoV-2 due to their immunocompromised states [5]. Thirdly, SARS-CoV-2 has been shown to potentially cause dysfunction in multiple organs, including respiratory, cardiovascular, neurological, immunological, and gastrointestinal systems [6-11]. Dysfunction of single or multiple organ systems will further complicate the prognosis and management of cancers.

Hepatocellular carcinoma (HCC) is the sixth most common cancer in the world, which accounts for approximately $6 \%$ of all cancer incidences [12]. For the past decade, while there has been a reduction in cases of HCC in Asia, the incidence of HCC has gradually increased in Western countries, rendering HCC a more global health problem $[13,14]$. Compared to other cancers, HCC patients are more susceptible to the effects of the COVID-19 pandemic because the hepatic injury (discussed further below) caused by SARS-CoV-2 could complicate the existing hepatitis virus infection and cirrhosisin most HCC patients. Furthermore, management of HCC relies heavily on multidisciplinary approaches involving hepatobiliary surgeons, interventional radiologists, hepatologists, and oncologists, which are susceptible to disruption of the stressed medical system during the pandemic [15]. Extra coordination is necessary amongst different specialties to maintain clinical services to patients with HCC. This article aims to review the literature on the impact of the COVID-19 on HCC and discuss the interim measures on the management of HCC during and after the COVID-19 pandemic.

\section{Impact of COVID-19 on the Liver}

Current data, mainly retrospective cohort studies, show that $15-54 \%$ of patients with confirmed COVID-19 have hepatic injury, typically manifested as an elevation of alanine aminotransferase (ALT) and/or aspartate aminotransferase (AST), which is occasionally accompanied by a mild degree of hyperbilirubinemia (Table 1) [2, 4, 16-21]. Raised gammaglutamyl transferase has also been reported in up to $54 \%$ of patients with COVID-19, and 


\begin{tabular}{|c|c|}
\hline iver Cancer 2020;9:491-5 & \\
\hline DOI: 10.1159/000510765 & $\begin{array}{l}\text { (c) } 2020 \text { The Author(s). Published by S. Karger AG, Basel } \\
\text { www.karger.com/lic }\end{array}$ \\
\hline
\end{tabular}

Table 1. Rate of abnormal liver function tests in patients with COVID-19

\begin{tabular}{|c|c|c|c|}
\hline Study & Sample size, $n$ & $\begin{array}{l}\text { Pre-existing chronic liver } \\
\text { disease/liver conditions, \% }\end{array}$ & Abnormal liver functions \\
\hline Huang et al. [17] & 41 & 2.4 & Elevation of AST: $36.6 \%$ \\
\hline Guan et al. [2] & 1,099 & 2.1 & $\begin{array}{l}\text { Elevation of AST: } 22.2 \% \text {; ALT: } 21.3 \% \text {; } \\
\text { total bilirubin: } 10.5 \%\end{array}$ \\
\hline Cai et al. [53] & 298 & 2.7 & $\begin{array}{l}\text { Elevation of AST: } 8.7 \% \text {; ALT: } 8.7 \% \text {; } \\
\text { total bilirubin: } 3.1 \%\end{array}$ \\
\hline Fan et al. [54] & 148 & 5.4 & $\begin{array}{l}\text { Elevation of AST: } 21.6 \% \text {; ALT: } 18.2 \% \text {; } \\
\text { total bilirubin: } 6.1 \%\end{array}$ \\
\hline Wang et al. [19] & 138 & 2.9 & $\mathrm{~N} / \mathrm{A}$ \\
\hline Shi et al. [18] & 81 & 8.6 & Elevation of AST: $53.1 \%$ \\
\hline Xu et al. [20] & 62 & 11.3 & Elevation of AST: $16.1 \%$ \\
\hline Yang et al. [4] & 52 & $\mathrm{~N} / \mathrm{A}$ & $28.8 \%^{\mathrm{a}}$ \\
\hline Zhang et al. [23] & 56 & 3.6 & $28.6 \%{ }^{\mathrm{a}}$ \\
\hline
\end{tabular}

alkaline phosphatase (ALP) may be disproportionately increased compared to ALT/AST levels [22, 23]. In most patients, the hepatic injury is transient but permanent damage has been reported in severe cases of COVID-19 $[16,23]$. The degree of hepatic dysfunction is also worse in patients with more severe COVID-19 [2,17].

The mechanism of hepatic injury is likely multifactorial (Fig. 1). Direct cytopathic effects of the virus on hepatocytes and/or cholangiocytes via the angiotensin-converting enzyme 2 receptor, immune-mediated inflammation, and hypoxia from pneumonitis have been postulated to be potential mechanisms [9, 22]. An indirect mechanism, especially the drug-related hepatotoxicity, is also possible (Fig. 1) because patients with severe COVID-19 are usually treated with multiple antivirals, antibiotics, and supportive agents. Amongst those agents, lopinavir/ritonavir could increase liver enzyme levels, and the administration of tocilizumab for disease-induced cytokine release syndrome is associated with increased AST/ALT levels and risk of toxic hepatitis [24].

Globally, approximately 1.5 billion people have chronic liver disease, mainly due to viral hepatitis and alcoholic and non-alcoholic fatty liver disease [25, 26]. According to different reported series of COVID-19, 2-11\% of patients have comorbid liver disease [2, 4, 16-20]. Amongst these patients, COVID-19 could inflict additional hepatic injury or even hepatic decompensation in patients with compromised hepatic reserves. In addition, the potential immunosuppressive property induced by the SARS-CoV-2 may lead to viral reactivation in patients with chronic viral hepatitis [27,28]. In response to hepatic injury caused by COVID-19, most guidelines recommend an assessment of hepatic function, including ALT, AST, ALP, GGT, albumin and total protein, total bilirubin, and prothrombin time, in patients with a diagnosis of COVID-19 [29, 30]. More intensive monitoring is indicated for severe cases or patients treated with tocilizumab or lopinavir/ritonavir. In the case of jaundice or hyperbilirubinemia, the need for imaging or endoscopic procedures should be judiciously balanced against the risk of unnecessary exposure of patients and healthcare providers. 
Fig. 1. Impact of SARS-CoV-2 on the liver and HCC.

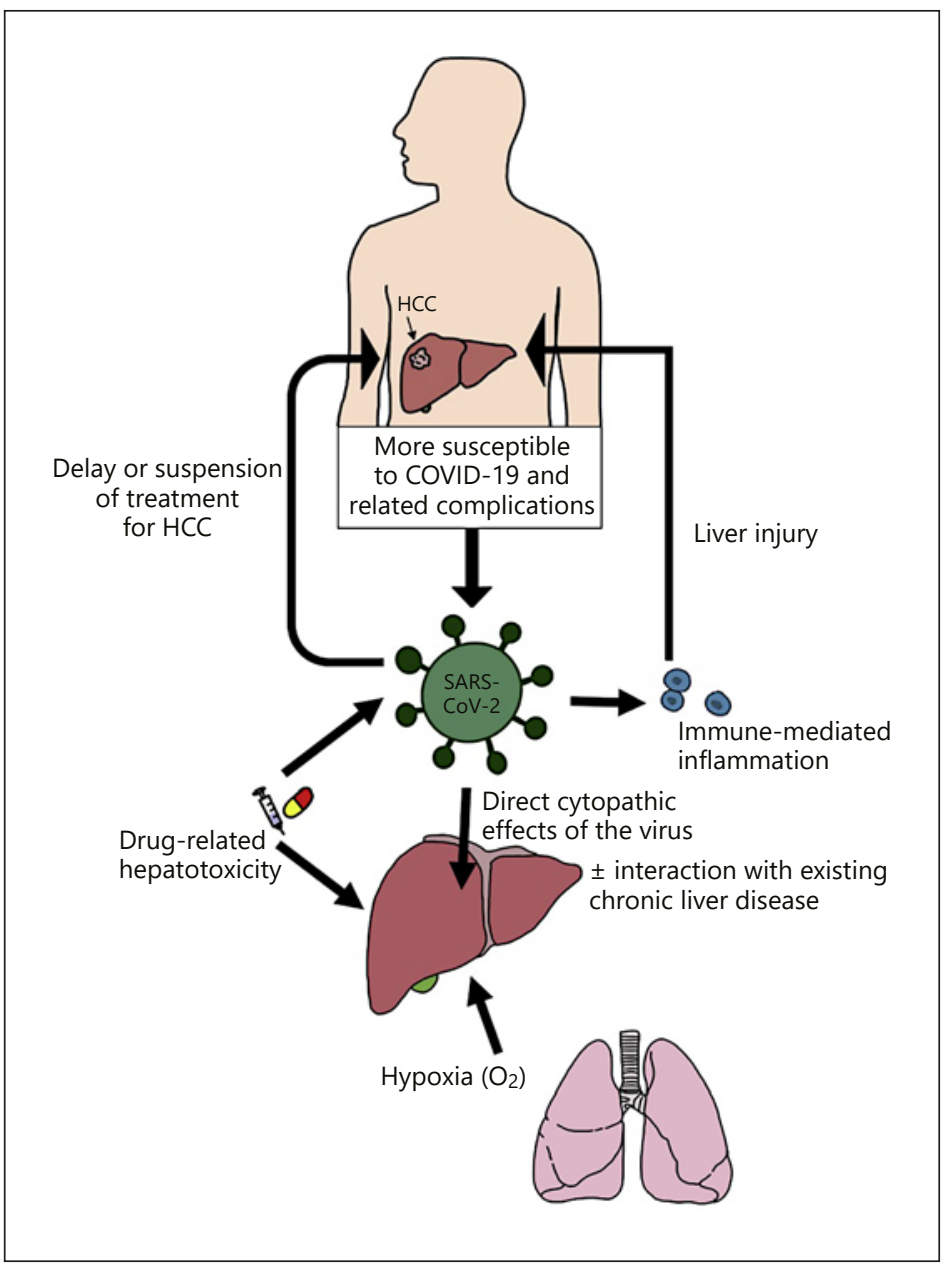

\section{Impact of COVID-19 on Cancers}

A number of cohort studies on COVID-19 amongst cancer patients or survivors has been reported, with the key findings summarized in Table 2. Several observations can be made from those studies. Firstly, patients with cancer are at a higher risk of suffering from COVID-19 than non-cancer patients. According to a cohort study of cancer patients in China, risk factors for the development of COVID-19 include a diagnosis of non-small cell lung cancer and an age above 60 years [5]. Secondly, it was generally demonstrated that the development of COVID-19 in cancer patients was associated with worse outcomes, including a higher admission rate to intensive care units and higher mortality, than in non-cancer COVID patients [5, 31, 32]. For example, a study identified 18 patients with a history of cancer from a prospective 1,590patient national database of COVID-19 in China [31]. In the study, it was shown that cancer patients had a shorter median time to deterioration (13 days) as compared to 43 days in patients without cancer. In the same report, there was also a higher chance of severe events, defined as admission to an intensive care unit requiring invasive ventilation or death, in cancer patients (39\%) than in patients without cancer (8\%). Thirdly, apart from the history of cancer, recent cancer treatment may also exacerbate the outcome of COVID-19. According to one retrospective study of cancer patients with COVID-19 infection in three hospitals in Wuhan, having had cancer treatment within the previous 14 days was associated with a 
Chan and Kudo: SARS-CoV-2 and HCC

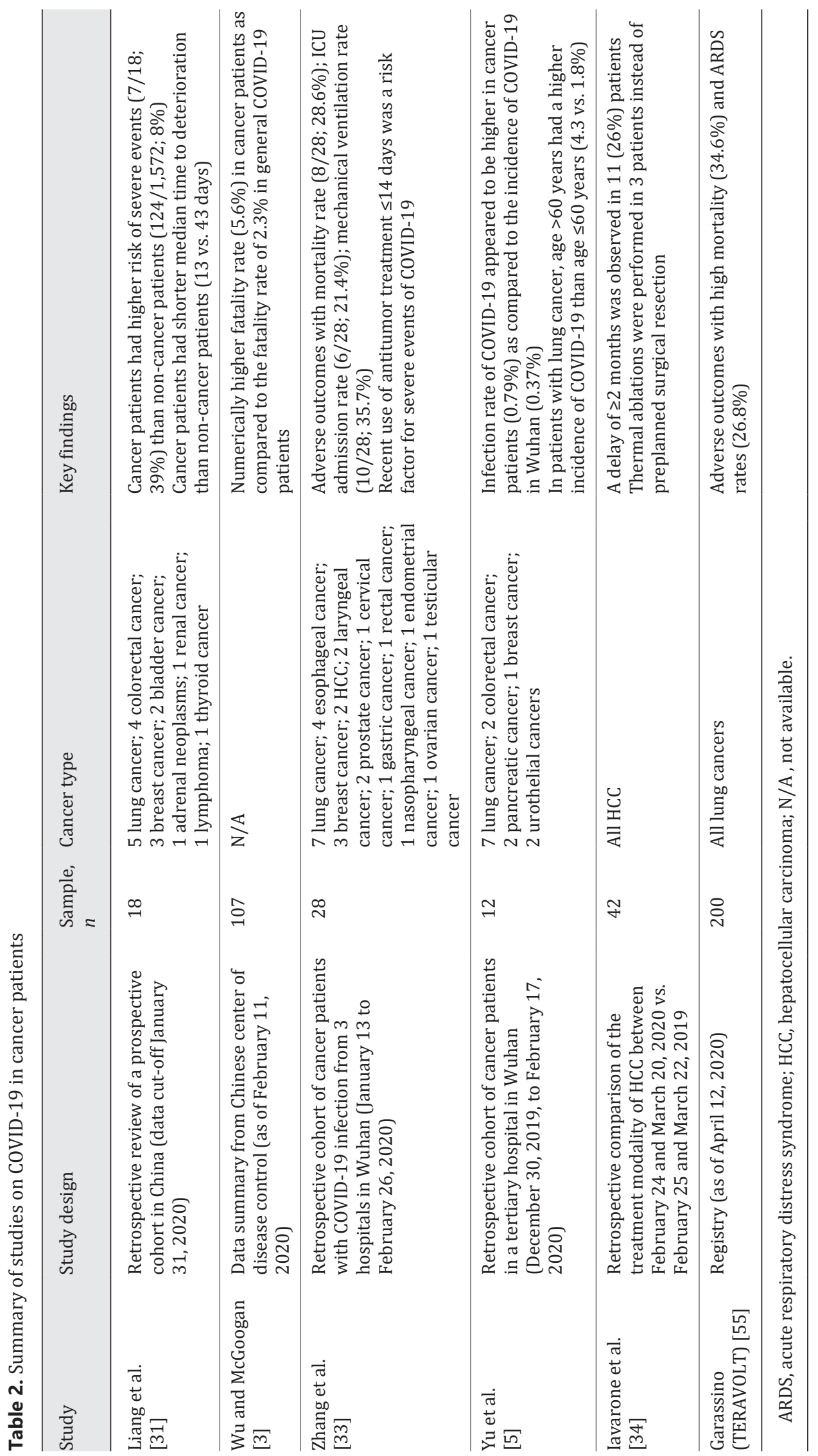


igher risk of adverse events (hazard ratio $=4.1 ; p=0.037$ ) [33]. The authors of the study suggested anticancer treatment-related immunosuppression to be a main reason for the poor outcomes [33]. However, further delineation of etiology between the specific type of treatment and adverse events was not possible in the study due to the small sample size with highly heterogeneous treatment modalities.

\section{Impact of COVID-19 on Liver Cancers}

HCC is underrepresented in most currently available studies on cancer patients with COVID-19 infection (Table 2). In data from China, only 2 HCC patients were recruited in the retrospective series [33]. More robust experience with HCC came from a series reported by an Italian center [34]. The group has handled the COVID-19 crisis by modifying clinical practices in the management of HCC to minimize patients' exposure to the virus. In the study, the authors compared 42 HCC patients between February 24 and March 20, 2020 (during the COVID-19 outbreak in Italy) to patients treated during the same period in 2019 (before the COVID-19 outbreak), and found that 11 patients (26\%) had delay of treatment of 2 months or longer [34]. The modalities of delayed treatment were mostly trans-arterial procedures (8 patients), followed by thermal ablation ( 3 patients) and systemic treatment ( 2 patients). In the study, all three thermal ablations were performed as alternative treatments to surgeries. Although it is unclear whether these modification and delays will significantly affect the longterm outcomes of HCC, this study represents the best effort that clinicians have made to help patients with HCC during this difficult period. It is expected that influences will be more significant in regions with a high incidence of HCC. Therefore, additional coordination may be required to unify the arrangement of adjusting treatment amongst different specialties according to the latest local COVID-19 situation.

\section{Modification of Management of HCC during the COVID-19 Pandemic}

Given the limitations imposed by the pandemic, a consensus amongst clinicians has been that deviations from the standard of care are necessary during the management of HCC. Guidelines on cancer management have been drafted by the international cancer organization (e.g., American Society of Clinical Oncology [ASCO] [35] and the European Society of Medical Oncology [ESMO] [36]) or local guidelines (e.g., the National institute for Heath and Care Excellence [NICE] [37] in the UK). Specific guidelines on liver disease and HCC have also been published by the American Association for the Study of Liver Disease (AASLD), The European Association for the Study of the Liver (EASL) [38], and the International Liver Cancer Association (ILCA) [30], respectively.

The first principle of modification of clinical practice is to defer treatment to reduce the spread of SARS-CoV-2 amongst cancer patients. The second principle is to modify treatment according to the best evidence and availability of resources in each specialty. Modifications should made in the context of multidisciplinary settings with clear documentation so that principles of clinical governance and accountability are maintained. This may also facilitate the collection of data for future study on the impact of COVID-19 on

cancer outcomes. During consultations, patients should be made aware of the impact of COVID-19 on treatment options and the risks and benefits should be fully discussed to enable them to make an informed decision. While the extent of the negative impact on clinical care for HCC patients remains unclear and may vary between settings, regions, and countries, it is important to review the impact on cancer treatment and explore the alter-

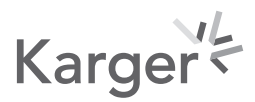




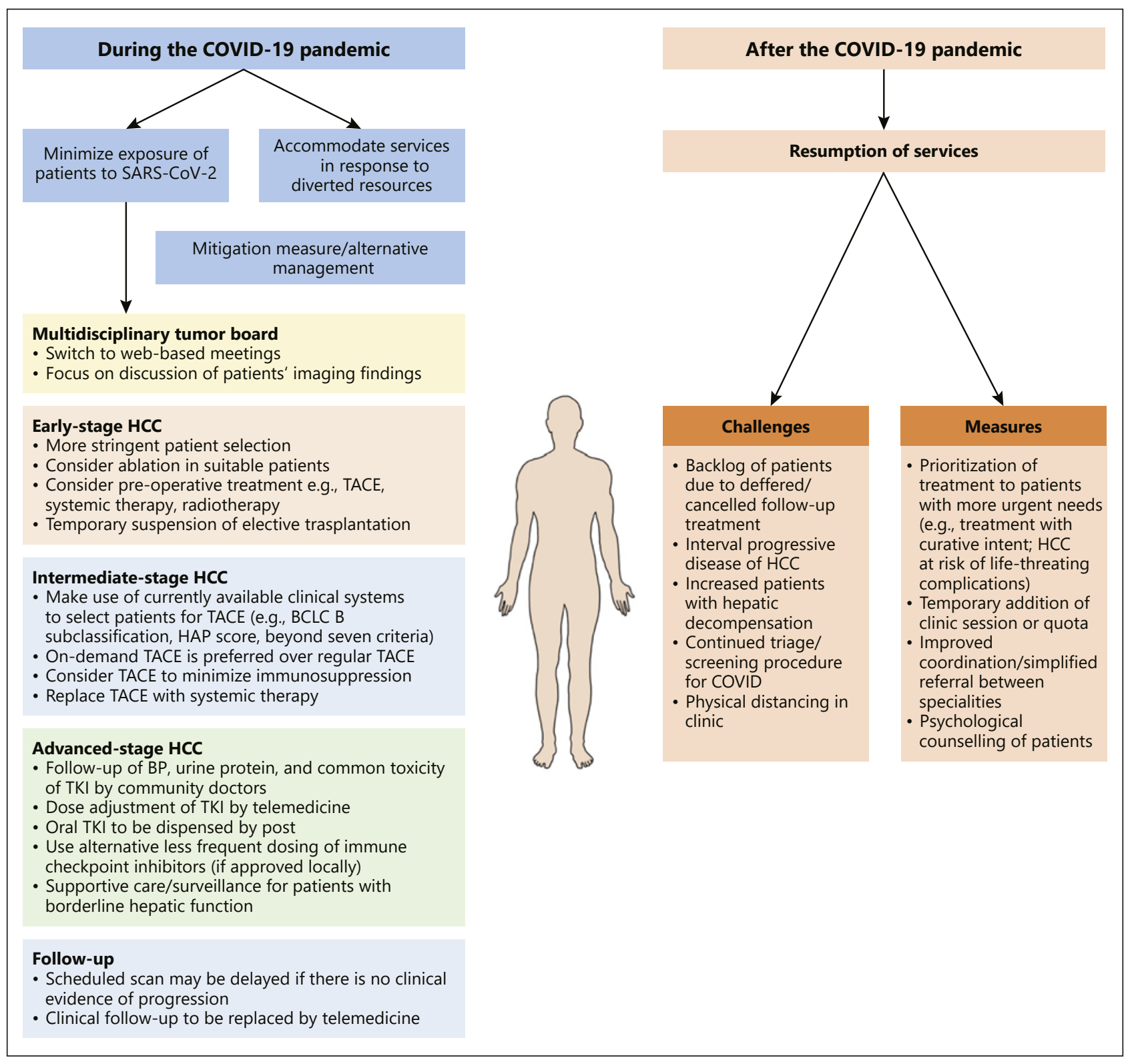

Fig. 2. Modification of management during the COVID-19 pandemic and considerations for resuming ordinary services after recovery from the pandemic.

native options when resources are limited. Figure 2 illustrates the potential interim measures on the management of HCC during the COVID-19 pandemic. A few areas have been highlighted for discussion below.

\section{Multidisciplinary Team Tumor Board}

Multidisciplinary team meetings amongst different specialties is preferably switched to web-based meetings as part of social distancing measures. Since radiological features play a crucial role in deciding the treatment modality for HCC, online discussion of imaging, together with clinical information, should be able to help shortlist or decide the suitable treatment 
modality for most patients. The local COVID-19 conditions and its impact on delivery of treatment in each specialty should also be considered during the process of decision making for the treatment of HCC.

\section{Early-Stage HCC}

The capacity of individual centers for surgical resection may be reduced by a shortage of intensive care unit beds and anesthetic facilities during the COVID-19 pandemic. To reduce waiting times for surgery and avoid interval progression during waiting, clinicians could prioritize surgery for patients with a smaller disease burden. Alternative definitive treatment, such as radiofrequency and microwave ablation, may be considered for cases with a tumor size and number within the criteria for complete ablation [39]. For HCC beyond ablation limits, upfront trans-arterial treatment [40], systemic treatment [41, 42], and radiotherapy [43] may be considered in centers where radiological and oncological services are less affected by the pandemic. Liver transplant services may also be slowed down or temporarily suspended for HCC due to a shortage of donors and reduced anesthetic capacity.

\section{Intermediate-Stage HCC}

At centers in which transarterial chemoembolization (TACE) services are affected by the pandemic, more selective criteria may be applied to identify patients who are expected to derive more benefits from TACE. In the literature, a number of clinical systems, such as the Barcelona clinic liver cancer stage B subclassification [44], the HAP score [45], and the "beyond-up-to-seven" criteria [46], have been reported to stratify outcomes of patients undergoing TACE. Based on local experience, a multidisciplinary team may make decisions on the choice of clinical systems and corresponding cut-off criteria to select patients for commencing TACE. For the subsequent TACE, an on-demand approach is preferred to a regular treatment approach. In case TACE services cannot readily be given to patients, systemic treatment or surveillance with regular imaging may be an alternative approach for intermediate-stage HCC [30].

\section{Advanced-Stage HCC}

To reduce travelling times and frequencies, patients treated with oral multitargeted tyrosine kinase inhibitors may be followed up in clinics at longer intervals during the pandemic. If applicable, patients' tolerance and clinical status may be monitored by telephone consultation or another telemedicine interface when frequent clinical visits are not feasible. Management of less complicated toxicities, such as hypertension, dermatological problems, and diarrhea, may be handled by community doctors after coordination with parent teams. For immune checkpoint inhibitors, a less frequent schedule of infusion may be considered if the risks of travel are considered excessively high. For nivolumab and pembrolizumab, alternative less frequent dosing regimen have been reported in other cancer types, which may be extrapolated to be used in HCC patients during the pandemic $[47,48]$.

\section{Clinical Trials}

Regulatory bodies have published guidance on handling clinical trials in response to the pandemic, with the main principle being the flexibility of implementing trial procedures to protect patients [49-51]. Due to social distancing policies in most countries, the number of protocol deviations is expected to increase during the pandemic. It is important for investigators to document protocol deviations and closely communicate with regulators and sponsors. Safety of trial participants should always be the top consideration in decision making and following of clinical trial procedures. Therefore, the risk/benefit assessment should be continuously monitored during conduct of clinical trials while the pandemic is

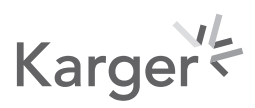


ongoing. In any case, if a trial subject is at excessive risk due to trial procedures or treatments, modification or even interruption of accrual is indicated. When supply of study medications is interrupted, patients should be considered for alternative drug treatments for HCC. For example, sorafenib or lenvatinib may be supplied as an interim treatment during the cessation period [30]. On-site monitoring may be challenging in areas with a high incidence rate of COVID-19. Alternative monitoring strategies should be decided amongst sponsors, the clinical research organization, and investigators, with particular consideration of patient and data confidentiality. Remote monitoring focusing on more important data on patient safety and data quality may be a reasonable alternative.

\section{Considerations on the Resumption of Services after the Pandemic}

It is foreseeable that the COVID-19 pandemic will resolve gradually in the future, and most medical services will be resumed afterwards. For HCC, four considerations are essential during planning for the resumption of ordinary services (Fig. 2). Firstly, a rebound in the number of patients and appointments is unavoidable due to the backlog of deferred or cancelled appointments during the pandemic. To accommodate the surge in demand, a wellstructured triage strategy is required to prioritize clinical appointments, investigations, and treatments to patients with more imminent needs, with examples including those with HCCs amenable to treatment with curative intent or patients at risk of a ruptured tumor. An extra clinic session or quota may be required to cater for the demand, although this is expected to be very challenging in the first few months of service resumption. Secondly, interval progression of HCCs may have occurred in patients with a more aggressive tumor biology during the pandemic as a result of the delay or cessation of treatment. The proportion of patients with more advanced HCC may also increase due to interruption of surveillance programs in cirrhotic or high-risk patients. Additional resources may be required to offer treatment for these groups of patients. Thirdly, it is anticipated that cirrhotic patients may be more prone to hepatic decompensation during the social lockdown period as a result of highrisk behavior such as increased alcohol intake, consumption of high-salt processed food, and lack of assess to supportive medications/antivirals, etc. [52]. The worsened hepatic function in these patients will inevitably complicate the management plan of HCC. More aggressive treatment (e.g., diuretics) and monitoring of hepatic function may be required prior to commencing treatment for HCC in these patients. Finally, precautionary measures will still be required to prevent the spread of SARS-CoV-2 within clinical areas in case of a return of the outbreak. Therefore, triage procedures including screening of respiratory symptoms, temperature checking, screening of travel and contact history should still be implemented for every visiting patient according to the local guidance. Physical distancing, including limiting the number of patients and accompanying individuals, in the clinical area should be considered.

\section{Future Directions}

There remain a few pertinent questions regarding the impact of the pandemic on HCC. Considering HCC patients who are diagnosed with COVID-19, do they differ from other cancer COVID-19 patients in terms of prognoses and hepatic dysfunction? For general HCC patients, how does the modification of clinical practice during the pandemic affect the outcomes of patients? Are patients receiving immune checkpoint inhibitors more susceptible to COVID-19 or its related complications? The answers to these questions are unknow at this juncture, but with more data emerging from different countries it is expected that some may be addressed in the nearest future.

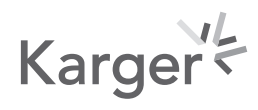


Chan and Kudo: SARS-CoV-2 and HCC

\section{Conclusion}

The COVID-19 pandemic has become a major public health challenge to the integrity of healthcare systems in many countries, and its negative impact on medical care for cancer patients is a concern. During the pandemic, interim adjustment of clinical management is necessary to minimize patients' risk to the infection and divert resources to handle the outbreak. When the community is gradually recovering from the pandemic, the medical field is also expected to face challenges during the resumption of clinical services for HCC patients.

\section{Conflict of Interest Statement}

Stephen L. Chan has acted as an advisor to AstraZeneca, Eisai, MSD, and Novartis, received research grants from Bayer, Ipsen, and SIRTEX, and received lecture fees from AstraZeneca, Bayer, Eisai, and MSD. Masatoshi Kudo has acted as an advisor to Eisai, Ono, MSD, Bristol-Myers Squibb, Roche, and AstraZeneca, received research grants from Gilead Sciences, Taiho, Sumitomo Dainippon Pharma, Takeda, Otsuka, EA Pharma, AbbVie, and Eisai, and received lecture fees from Eisai, Bayer, MSD, and Bristol-Myers Squibb Lilly.

\section{Funding Sources}

There were no funding sources in relation to this work.

\section{Author Contributions}

Both authors (S.L.C. and M.K) contributed to the conception, data collection, drafting, and approval of the manuscript.

\section{References}

1 World Health Organization. Coronavirus disease (COVID-19) pandemic. 2020. https://www.who.int/emergencies/diseases/novel-coronavirus-2019.

2 Guan WJ, Ni ZY, Hu Y, Liang WH, Ou CQ, He JX, et al; China Medical Treatment Expert Group for Covid-19. Clinical characteristics of coronavirus disease 2019 in China. N Engl J Med. 2020 Apr;382(18):1708-20.

3 Wu Z, McGoogan JM. Characteristics of and Important Lessons From the Coronavirus Disease 2019 (COVID-19) Outbreak in China: Summary of a Report of 72314 Cases From the Chinese Center for Disease Control and Prevention. JAMA. 2020 Feb;323(13):1239.

4 Yang X, Yu Y, Xu J, Shu H, Xia J, Liu H, et al. Clinical course and outcomes of critically ill patients with SARSCoV-2 pneumonia in Wuhan, China: a single-centered, retrospective, observational study. Lancet Respir Med. 2020 May;8(5):475-81.

5 Yu J, Ouyang W, Chua MLK, Xie C. SARS-CoV-2 transmission in patients with cancer at a tertiary care hospital in Wuhan, China. JAMA Oncol. 2020;6(7):1108-10.

6 Mehra MR, Desai SS, Kuy S, Henry TD, Patel AN. Cardiovascular disease, drug therapy, and mortality in Covid-19. N Engl J Med. 2020 May;382(26):2582.

7 Tay MZ, Poh CM, Renia L, MacAry PA, Ng LFP. The trinity of COVID-19: immunity, inflammation and intervention. Nat Rev Immunol. 2020;20(6):363-74.

8 Wang T, Du Z, Zhu F, Cao Z, An Y, Gao Y, et al. Comorbidities and multi-organ injuries in the treatment of COVID-19. Lancet. 2020 Mar;395(10228):e52.

9 Wong SH, Lui RN, Sung JJ. Covid-19 and the digestive system. J Gastroenterol Hepatol. 2020 May;35(5):744-8.

10 Wu Y, Xu X, Chen Z, Duan J, Hashimoto K, Yang L, et al. Nervous system involvement after infection with COVID-19 and other coronaviruses. Brain Behav Immun. 2020 Jul;87:18-22.

11 Zheng YY, Ma YT, Zhang JY, Xie X. COVID-19 and the cardiovascular system. Nat Rev Cardiol. 2020 May;17(5): 259-60.

12 Siegel RL, Miller KD, Jemal A. Cancer statistics, 2020. CA Cancer J Clin. 2020 Jan; 70(1):7-30.

13 Nordenstedt $\mathrm{H}$, White DL, El-Serag HB. The changing pattern of epidemiology in hepatocellular carcinoma. Dig Liver Dis. 2010 Jul;42 Suppl 3:S206-14. 


\begin{tabular}{|c|c|}
\hline Liver Cancer 2020;9:491-502 & \\
\hline DOI: 10.1159/000510765 & $\begin{array}{l}\text { (c) } 2020 \text { The Author(s). Published by S. Karger AG, Basel } \\
\text { www.karger.com/lic }\end{array}$ \\
\hline
\end{tabular}

Chan and Kudo: SARS-CoV-2 and HCC

14 Goh GB, Chang PE, Tan CK. Changing epidemiology of hepatocellular carcinoma in Asia. Best Pract Res Clin Gastroenterol. 2015;29(6):919-28.

15 Cohen GS, Black M. Multidisciplinary management of hepatocellular carcinoma: a model for therapy. J Multidiscip Healthc. 2013 May; 6:189-95.

16 Chen N, Zhou M, Dong X, Qu J, Gong F, Han Y, et al. Epidemiological and clinical characteristics of 99 cases of 2019 novel coronavirus pneumonia in Wuhan, China: a descriptive study. Lancet. 2020 Feb;395(10223):50713.

17 Huang C, Wang Y, Li X, Ren L, Zhao J, Hu Y, et al. Clinical features of patients infected with 2019 novel coronavirus in Wuhan, China. Lancet. 2020 Feb;395(10223):497-506.

18 Shi H, Han X, Jiang N, Cao Y, Alwalid O, Gu J, et al. Radiological findings from 81 patients with COVID-19 pneumonia in Wuhan, China: a descriptive study. Lancet Infect Dis. 2020 Apr;20(4):425-34.

19 Wang D, Hu B, Hu C, Zhu F, Liu X, Zhang J, et al. Clinical characteristics of 138 hospitalized patients with 2019 novel coronavirus-infected pneumonia in Wuhan, China. JAMA. 2020;323(11):1061-9.

$20 \mathrm{Xu}$ XW, Wu XX, Jiang XG, Xu KJ, Ying LJ, Ma CL, et al. Clinical findings in a group of patients infected with the 2019 novel coronavirus (SARS-Cov-2) outside of Wuhan, China: retrospective case series. BMJ. 2020; 368:m606.

21 Zhao D, Yao F, Wang L, Zheng L, Gao Y, Ye J, et al. A comparative study on the clinical features of COVID-19 pneumonia to other pneumonias. Clin Infect Dis. 2020 Jul;71(15):756-61.

$22 \mathrm{Xu}$ L, Liu J, Lu M, Yang D, Zheng X. Liver injury during highly pathogenic human coronavirus infections. Liver Int. 2020 May;40(5):998-1004.

23 Zhang C, Shi L, Wang FS. Liver injury in COVID-19: management and challenges. Lancet Gastroenterol Hepatol. 2020 May;5(5):428-30.

24 Genovese MC, Kremer JM, van Vollenhoven RF, Alten R, Scali JJ, Kelman A, et al. Transaminase Levels and Hepatic Events During Tocilizumab Treatment: Pooled Analysis of Long-Term Clinical Trial Safety Data in Rheumatoid Arthritis. Arthritis Rheumatol. 2017 Sep;69(9):1751-61.

25 Disease GB, Injury I, Prevalence C; GBD 2017 Disease and Injury Incidence and Prevalence Collaborators. Global, regional, and national incidence, prevalence, and years lived with disability for 354 diseases and injuries for 195 countries and territories, 1990-2017: a systematic analysis for the Global Burden of Disease Study 2017. Lancet. 2018 Nov;392(10159):1789-858.

26 Moon AM, Singal AG, Tapper EB. Contemporary Epidemiology of Chronic Liver Disease and Cirrhosis. Clin Gastroenterol Hepatol. 2019 Aug;S1542-3565(19)30849-3.

27 Kumar D, Tellier R, Draker R, Levy G, Humar A. Severe Acute Respiratory Syndrome (SARS) in a liver transplant recipient and guidelines for donor SARS screening. Am J Transplant. 2003 Aug;3(8):977-81.

28 Xu Z, Shi L, Wang Y, Zhang J, Huang L, Zhang C, et al. Pathological findings of COVID-19 associated with acute respiratory distress syndrome. Lancet Respir Med. 2020 Apr;8(4):420-2.

29 AASLD. Clinical best practice advice for hepatology and liver transplant providers during the COVID-19 pandemic: AASLD expert panel consensus statement. 2020. https://www.aasld.org/sites/default/ files/2020-05/AASLD-COVID19-ClinicalInsights-May42020-FINAL.pdf.

30 Meyer T, Chan S, Park JW. Management of HCC during COVID-19: ILCA guidance. ILCA, 2020. https://ilcaonline.org/wp-content/uploads/2020/04/webinar-on-management-of-hcc-during-covid-19_-ilca-guidance-pdf.pdf.

31 Liang W, Guan W, Chen R, Wang W, Li J, Xu K, et al. Cancer patients in SARS-CoV-2 infection: a nationwide analysis in China. Lancet Oncol. 2020 Mar;21(3):335-7.

32 Xia Y, Jin R, Zhao J, Li W, Shen H. Risk of COVID-19 for patients with cancer. Lancet Oncol. 2020 Apr;21(4):e180.

33 Zhang L, Zhu F, Xie L, Wang C, Wang J, Chen R, et al. Clinical characteristics of COVID-19-infected cancer patients: a retrospective case study in three hospitals within Wuhan, China. Ann Oncol. 2020;31(7):894-901.

34 Iavarone M, Sangiovanni A, Carrafiello G, Rossi G, Lampertico P. Management of hepatocellular carcinoma in the time of COVID-19. Ann Oncol. 2020 Aug;31(8):1084-5.

35 ASCO. COVID-19 patient care information. 2020. https://www.asco.org/asco-coronavirus-information/careindividuals-cancer-during-covid-19 (accessed April 2, 2020).

36 ESMO. Cancer patient management during the COVID-19 pandemic. 2020. https://www.esmo.org/guidelines/cancer-patient-management-during-the-covid-19-pandemic.

37 NICE. COVID-19 rapid guideline: delivery of systemic anticancer treatments. 2020. https://www.nice.org.uk/ guidance/ng161.

38 EASL. EASL-ESCMID position paper: patients with advanced liver disease and transplant recipients require specific care during COVID-19. 2020. https://easl.eu/news/easl-escmid-position-paper-on-covid19-and-theliver.

39 Galle PR, Forner A, Llovet JM, Mazzaferro V, Piscaglia F, Raoul JL, et al. EASL clinical practice Guidelines: management of hepatocellular carcinoma. J Hepatol. 2018 Jul;69(1):182-236.

40 Gabr A, Abouchaleh N, Ali R, Baker T, Caicedo J, Katariya N, et al. Outcomes of surgical resection after radioembolization for hepatocellular carcinoma. J Vasc Interv Radiol. 2018 Nov;29(11):1502-10.e1.

41 Barbier L, Fuks D, Pessaux P, Muscari F, Le Treut YP, Faivre S, et al. Safety of liver resection for hepatocellular carcinoma after sorafenib therapy: a multicenter case-matched study. Ann Surg Oncol. 2013 Oct;20(11): 3603-9. 
42 Kaseb A, Vence L, Blando J, Yadav S, Ikoma N, Pestana R, et al. Randomized, open-label, perioperative phase II study evaluating nivolumab alone versus nivolumab plus ipilimumab in patients with resectable HCC. Ann Oncol. 2019;30(suppl 4):iv112.

43 Kim N, Cheng J, Jung I, Liang J, Shih YL, Huang WY, et al. Stereotactic body radiation therapy vs. radiofrequency ablation in Asian patients with hepatocellular carcinoma. J Hepatol. 2020 Jul;73(1):121-9.

44 Bolondi L, Burroughs A, Dufour JF, Galle PR, Mazzaferro V, Piscaglia F, et al. Heterogeneity of patients with intermediate (BCLC B) Hepatocellular Carcinoma: proposal for a subclassification to facilitate treatment decisions. Semin Liver Dis. 2012 Nov;32(4):348-59.

45 Kadalayil L, Benini R, Pallan L, O’Beirne J, Marelli L, Yu D, et al. A simple prognostic scoring system for patients receiving transarterial embolisation for hepatocellular cancer. Ann Oncol. 2013 Oct;24(10):2565-70.

46 Kudo M, Ueshima K, Chan S, Minami T, Chishina H, Aoki T, et al. Lenvatinib as an initial treatment in patients with intermediate-stage hepatocellular carcinoma beyond up-to-seven criteria and Child-Pugh A liver function: a proof-of-concept study. Cancers. 2019 Jul;11(8):E1084.

47 Long GV, Tykodi SS, Schneider JG, Garbe C, Gravis G, Rashford M, et al. Assessment of nivolumab exposure and clinical safety of $480 \mathrm{mg}$ every 4 weeks flat-dosing schedule in patients with cancer. Ann Oncol. 2018 Nov; 29(11):2208-13.

48 Lala M, Li TR, de Alwis DP, Sinha V, Mayawala K, Yamamoto N, et al. A six-weekly dosing schedule for pembrolizumab in patients with cancer based on evaluation using modelling and simulation. Eur J Cancer. 2020 May; 131:68-75.

49 Medicines and Healthcare Products Regulatory Agency. Managing clinical trials during Coronavirus (COVID19). GOV.UK, 2020. https://www.gov.uk/guidance/managing-clinical-trials-during-coronavirus-covid-19.

50 European Medicines Agency. Guidance to sponsors on how to manage clinical trials during the COVID-19 pandemic. EMA, 2020. https://www.ema.europa.eu/en/news/guidance-sponsors-how-manage-clinicaltrials-during-covid-19-pandemic.

51 FDA. Guidance on conduct of clinical trials of medical products during COVID-19 public health emergency. 2020. https://www.fda.gov/media/136238/download.

52 Tapper EB, Asrani SK. The COVID-19 pandemic will have a long-lasting impact on the quality of cirrhosis care. J Hepatol. 2020 Aug; 73(2):441-5.

53 Cai Q, Huang D, Ou P, Yu H, Zhu Z, Xia Z, et al. COVID-19 in a designated infectious diseases hospital outside Hubei Province, China. Allergy. 2020;75(7):1742-52.

54 Fan Z, Chen L, Li J, Cheng X, Jingmao Y, Tian C, et al. Clinical features of COVID-19-related liver functional abnormality. Clin Gastroenterol Hepatol. 2020;18(7):1561-6.

55 Garassino MC. TERAVOLT (Thoracic Cancers International COVID-19 Collaboration): first results of a global collaboration to address the impact of COVID-19 in patients with thoracic malignancies. American Association for Cancer Research (AACR) Virtual Annual Meeting I, April 27-28, 2020. 